\title{
Enseñanza del castellano 1 ¿quo vadis?
}

\author{
LUIS MIRANDA ESQUERRE \\ Universidad Nacional Mayor de San Marcos
}

Quien no desea razonar es un fanático; el que no puede pensar es un idiota; y quienno tiene la valentía de pensar es un esclavo.

William Drumont

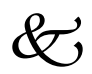

\section{Resumen}

El presente trabajo aborda uno de los más aciagas dramas nacionales: el problema de la enseñanza del castellano. El tema ha sido objeto de reflexión de múltiples foros y ha sido abordado por una gran cantidad de artículos de posición. El autor analiza las causas de la defectiva situación de la enseñanza del español y propone las posibles medidas que, en caso de asumirse, podrían sacamos del atolladero.

Sobre la base de hacer un efectivo diagnóstico de los graves errores del sistema educativo peruano, el estudioso expone sus ideas fundamentales sobre la escritura de textos, la lectura, el análisis gramatical y la austión lingüística penuana (nuestro rico e irreductible multilingüismo) .

La conclusión de las reflexiones anteriores nos conduce a una visión escéptica sobre el futuro de la enseñanza del castellano. Fn este sentido, el pesimismo del autor es, en el fondo, un llamado de atención: Urge un verdadero cambio de marcha en la política educativa penuana.

Palabras claves: Castellano, educación.

\section{Abstract}

The teaching of Spanish undergoes a severe crisis, as in shown in the great percentages of the population that has difficulties in understanding even simple texts and produces unintelligible texts; that the problem is generally known, is shown in several important national and intemational studies. Our study centers on showing the causes of the problem and its possible solutions. We consider it important to teach children and the young people to have a considerable command of Spanish; to center the teaching on the understanding and the production of texts and keep on a 


\begin{abstract}
second level the teaching of grammar and spelling and other aspects that correspond more to an explicit knowledge of the language that, furthermore, is not well taught, either. On the other hand, the problem is not only methooblogical; it has its roots in the social and economical situation of the country. There is no acces to the books necessary, the people camnot buy them and there hardly exist any public libraries; with respect to the ladking of educational politics (there is no national project in the branch of education), each government modifies the plans of study, not justifying anything at all. The forming of teachers is highly deficient. The teachers of the Spanish that finish their studies in the Faculties of Education and Pedagogical Institutes do nor always manage well this language and all their formation is centred on methodologies, not having really a solid formation in scientific knowledge, that they should teach. Usually it is not taken into account that Peru is a multilingual and multidialectal country, that there is a great variety of sociolectes and registers; all that should be taken into account and that without this consideration, the teaching of be Spanish will not be successful, but a failure.
\end{abstract}

Key words: Spanish. Education.

0 . El problema de la enseñanza del español es uno de los puntos cruciales en la crisis que atraviesa la educación en el Perú, por eso me parece importante el énfasis puesto en este punto por el presidente del CNE. ${ }^{2}$ Me refiero al documento de Ricardo Morales Basadre:

1. Ya la propia denominación de la asignatura en los planes de estudios es un error. En qué país de alto nivel educativo se le ocurriría a un funcionario llamar al curso de lengua materna comunicación en lugar de Français, English, Deutsch, etc. ; seguramente lo destituirían al instante:

Una primera y mu extendida forma de violencia que sufre la lengua, en la que todos prácticamente participamos, es el prejuicio que la define exclusivamente como un medio de comunicación. Si se la considera así -como lo hace muestra sociedad- se la violenta en el sentido que se olvida que el lenguaje -en particular el lenguaje poético- no es sólo medio, sino también el fin de la commicación. Cuando se mediatiza el lenguaje, cuando se lo considera sólo una mediación para otra mediación -porque la comunicación se pone al servicio del marketing, el marketing del dinero y así sucesiva e infinitamente- nos olvidamos de que el lenguaje es ante todo un placer, un placer sagrado; una forma, acaso la més elevada, de amor y conocimiento (Bordelois 2003: 11-12) . 
1.1. Se comunican los animales y también las máquinas, ¿cuál, pues, sería la diferencia con los seres humanos? El lenguaje no es commicación, salvo que se entienda por comunicación lo que tiene que ser común: compartido por una commidad de seres humanos. El lenguaje puede ser usado para commicar (intercambiar información) o para ocultar información, para expresar nuestros sentimientos, para comprender el mundo en que vivimos y la sociedad a la que pertenecemos, para engañar a la gente, etc. , pero en cada caso se trata de uno los múltiples usos que podemos dar al lenguaje y no de su esencia, que es significar. ${ }^{3}$

1.2. ¿Y lo de integral? , ¿se entiende, generalmente, como enseñar a la vez: «commicación» oral, «commicación» escrita, gramática, ortografía y razonamiento verbal?, es decir, de toob un poco ; se le enseña al niño muchas cosas a la vez, es decir, de manera superficial, por lo que termina no aprendiendo nada. Eso sí, la labor editorial se facilita, pues, los textos de los diferentes grados tienen el mismo formato. Con lo de integral, quizás, se pensó en los distintos sistemas de significar que utilizamos los seres humanos, pero resolver el problema necesita una información y una formación que, al parecer, no tuvieron los funcionarios y asesores del Ministerio de Educación. Santaella $(2001)^{6}$, por ejemplo, plantea que existen tres matrices de los sistemas de significar: la verbal, la visual y la virtual (por ejemplo, la música) yque toolos los otros sistemas son combinaciones de algunas de estas tres; el cine, por ejemplo, sería una combinación de todas.

2. ¿Es el Español la lengua común de todos los peruanos? Evidentemente no, salvo que desaparezcamos del mapa a los millones de hablantes de las más de 50 lenguas vernáculas (quechua, aimara y lenguas de la Amazonía) que existen en el territorio peruano.

¿Y cuando hablamos de Castellano a qué nos referimos? A una lengua sin variantes diatópicas, diastráticas y diafásicas. La diversidad del Español hablado en el Perú es muy grande, no se habla igual en Tumbes que en Loreto o en Cuzco; la gente de distintos estratos sociales lo habla de manera diferente y las variantes entre el uso formal e informal son también muy grandes. Inclusive hay relictos de Español arcaico en zonas aisladas del país, es decir, ¿diversidad diacrónica?7 Entonces, parte del problema es ¿qué castellano enseñar? 
2.1. Primero, debemos tener una idea clara de la realidad glotológica peruana y recién a partir de este conocimiento podremos saber qué Castellano enseñar, que probablemente no sea el mismo para cada región, departamento, provincia o distrito; nivel alto, medio o bajo; registro informal o formal. Todo lo que se haga desconociendo esta realidad está condenado al fracaso y eso es lo que está sucediendo ahora.

2.2. Asimismo, en la competencia glotológica hay que distinguir entre saber hablar, saber hablar una lengua y saber producir discursos (textos) , que son competencias relacionadas, pero con un buen grado de autonomía.

2.2.1. Cuando se menciona la relación entre lenguaje y pensamiento, probablemente de manera intuitiva, se remite tal referencia al primer saber, es decir, que el hablar debe ser congruente (regulado por los principios generales del pensamiento) .

2.2.2. El saber idiomático, la segunda competencia, se refiere al conocimiento de una lengua, que no es, como generalmente se piensa y dice: conocer la gramática y el diccionario de dicha lengua. Hecho que sería evidente, si nos detuviéramos a pensar en el caso de las lenguas que no cuentan con esos utensilios y, sin embargo, son habladas. Hay que distinguir entre el conocimiento intuitivo (implícito) del hablante (que habla la lengua) y el conocimiento explícito del gramático (que describe la lengua) .

2.2.3. El saber expresivo, la tercera competencia, se refiere a la capacidad de elaborar discursos (textos). Se habla siempre con una finalidad: convencer, pedir algo, ordenar, enseñar, etc. , y esto implica poder construir discursos de acuerdo con esos propósitos. Estas competencias son en cierto grado autónomas, se puede conocer poco una segunda lengua y hablarla congruentemente y/o pronunciar discursos convincentes; se puede conocer una lengua, pero no producir discursos adecuados (lo que pasa con muestros estudiantes, que tienen grandes dificultades para pasar al registro formal) . La enseñanza en el Perúr se ha centrado aparentemente en el saber idiomático, pero, además, no se distingue entre el conocimiento intuitivo del hablante y el explícito del gramático, de ahí la insistencia en enseñar gramática y no en ejercitar al estudiante en el uso del Castellano. Por otra parte, como se ignora la realidad glotológica peruana, se toma como lengua 
modelo (ejemplar) la que propugna la RAE, muy alejada de la realidad nuestra9. Esto hay que remarcarlo. ${ }^{10}$

2.3. Veamos lo que dice Manuel Seco (nww.edilgoras.com), autor de una gramática y un diccionario del Español mur reconocidos y, él mismo, miembro de la RAE:

La autoridad que desde un principio se atribuyó oficialmente a la academia en materia de lengua, unida a la alta calidad de la primera de sus doras, hizo que se implantase en muchos hablantes -españoles y americanos, hasta hoy, la idea que la Academia «dictamina» lo que debe y lo que no debe decirse. Incluso entre personas cultas es frecuente oír que tal o cual palabra «no está admitida» por la Academia y que por lo tanto «no es correcta» 0 《no existes.

En esta actitud respecto a la Academia hay un error fundamental, el de considerar que alguien -sea una persona o una corporación- tiene autoridad para legislar sobre la lengua. La lengua es de la commidad que la habla, y es lo que esta comnidad acepta lo que de verdad «existe», y es lo que el uso da por bueno lo único que en definitiva «es correcto». [...]

La actitud de reverencia ciega a la Academia, unida a la adhesión literal a uno de sus principios de fundación de ésta, da lugar a la posición purista, que rechaza cualquier palabra nueva por ser extranjera o simplemente por ser nueva. El punto de partida de esta postura es el de suponer que una lengua es una realidad fija, inmutable, perfecta; ignorando que tiene que cambiar al paso que cambia la sociedad que la habla, y que, al ser un instnumento al servicio de los hablantes, éstos la van adaptando siempre a la medida de sus necesidades.

\subsubsection{Nés duras, pero tan ciertas, son las críticas de Subirats (2000):}

No han faltado en nuestro país medidas científicamente banales cuya existencia únicamente se puede justificar en términos políticos en función de su rentabilidad mediática. Así, por ejemplo, la Real Academia ha sido destinataria en las últimas décadas de multimillonarias inversiones de dinero público, especialmente si se tiene en cuenta los escasos rearsos que se destinan en España a la investigación científica. Una parte mu importante de los medios económicos destinados en principio a la modemización de los instnmentos necesarios para el desarrollo de la lengua española (diccionarios, conpus textuales, etc.) han idb a parar a 
esta rancia institución. Una decisión insólita en el marco de la Unión Europea, donde las pocas Academias de la Lengua que existen todavía se han convertido en centros de documentación histórica sobre el papel que han tenido dichas instituciones en la consolidación de las lenguas nacionales.

Es cierto que, en la actualidad, la Acadenia se ha visto forzada a proyectar una imagen mediática distinta a la de hace unas décadas: la Real necesitaba urgentemente un cambio de imagen. Mbtivos no le faltan. En efecto, en un mundo de camunicaciones globales, resultaría no sólo inútil, sino incluso ridíalo, intentar justificar la necesidad de mantener una institución para fijar el uso lingüŕstico. Fn el entomo de las lenguas de aultura, no existe ninguna institución que pueda controlar o fijar su uso y, por supuesto, la Academia tampoco puede monitorizar el uso lingüístico de una commidad de cuatrocientos millones de hablantes. Es justamente esta realidad, la que ha llevado a algunos destacados académicos a justificar la existencia de la dosoleta Institución con argumentos no normativistas $y$, aparentemente, más modernos. Un buen ejemplo de esta actitud, nos lo brinda el académico Francisco Rico, cuando señala que «las academias no están para mantener un espacio, sino para permitir el sentidb natural de la lengua.» (El País, 07/ 09/00, p. 35) . El problema que plantea esta novedosa justificación es que para mantener «el sentido natural de la lengua» no es necesario mantener academias anacrónicas.

Quizás pueda resultar interesante anal izar algunos aspectos del proyecto lexicográfico de la real Institución, ya que dicho proyecto ha constituidb una de sus actividades fundamentales. Para empezar, resulta sonprendente constatar que los grandes diccionarios de la lengua española del siglo XX, concretamente el Diccionario de Uso del Español de María Mbliner (Madrid. Gredos, 1966) y el Diccionario del Español Actual de Manuel seco et al. (Madrid. Aguilar, 1999) han surgido al margen del Ente Glorioso. Y ello, por supuesto, no ha sucedido por casualidad. Ia actitud normativista de la Academia -al margen de sus vanos intentos por cambiar de imagen- ha sido un lastre para su actividad y constituye una muestra de su desvinculación con el uso real del español. Su lema pueril 'limpia, fija y da esplendor' , así como sus aburridas letanías sobre «los errores en el uso del idiama español», cuyo fundamento parte de consideraciones ajenas a la realidad del uso cotidiano de nuestra lengua, son esperpénticamente cómicas si se las confronta con el diccionario que la academia presenta como 'modelo' del uso de la lengua española para tooda la comnidadhispanchablante. Fh efecto, resulta difícil otorgarle 
un mínimo de credibilidad a esta longeva Institución, teniendb en cuenta que su Diccionario de la Lengua Española de 1995 comercializado en (DROM, no incluye palabras de uso común en la lengua española, como por ejemplo, y por citar tan solo unos ejemplos, acientífico, antialérgico, antitenorista, celulitis, ciraularidad, clasificable, cestacable, enfatización, etren, finalización, fluctuante, hindable, indisociable, iniciático, karadke, lanzamisiles, etc. Resulta asimismo gracioso que entre los boletines aratrimestrales (accesibles desde Intemet) en los que la Academia publica una relación de las ermiendas y adiciones al Diccionario que se van aprobando en sesión plenaria tampoco figuren las palabras mencionadas anteriormente (y algunas miles más...) . ¿Se trata acaso del primer Expediente X de la lexicografía española de la transición? [...] Pero volvamos de nuevo a ese desafortunado monumento del léxico español, me refiero, por supuesto, al Diccionario de la RAE. Resulta casi milagroso constatar que las definiciones de las religiones, a excepción de la católica, se consideran como 'sectas' . Así, haciendo propia la herencia del nacional-catolicismo, la Academia define protestante como 'persona que sigue el luteranismo o cualquiera de sus sectas' ....A la luz de esta breve consideración sobre la definición lexicográfica, resulta arrioso analizar la definición académica de menonugo:

«Pedazo de pan duro o desechado, y especialmente el sobrante que se suele dar a los mendigos.» (RAE 1992:958)

Se diría que la rancia Institución ha adoptado postmodemamente la enciclopedia china titulada Enporio celestial de Conocimientos Benévolos, descubierta por Borges, como fuente de inspiración secreta. Pero, ; ch! , constatamos con dolor que no hace más que reeditar lindamente y una vez más la definición del Diccicnario de Autoridades del siglo XVIII: «Mendrugo: El pedazo de pan que se suele dar a los mendigos [el subrayado es nuestro] » Diccionario de Autoridades, 1726-1739, p. 540.»

3. El sistema educativo, por lo menos, el peruano, sí es un complot ${ }^{11}$ contra la inteligencia y eso no es responsabilidad de los maestros, sino del sistema educativo, que está diseñado para acallar el pensamiento crítico, porque defiende los intereses de las clases dominantes a cuyo servicio siempre han estado los gobiernos. A un estudiante que ha cursado la primaria y la secundaria en el Perú le es casi imposible distinguir qué hay de verdad y qué hay de engaño en un discurso (texto) , es incapaz de confrontar lo que se dice con lo que se hace. Es como si lo hubieran domesticado para convertir los discursos en fetiches, el problema se reduce a la autoridad de quien produce el 
discurso (texto) : los padres, los amigos, los maestros y ahora, sobre toob, la televisión y la radio.

4. El problema de la lectura, generalmente, se enfoca mal. Se piensa que la escuela y el colegio son los responsables de que niños y jóvenes tengan problemas con la lectura. Es verdad que la escuela tiene alguna responsabilidad en la situación, porque no se ha entendido que no se trata de algo mecánico y que es un problema de educación a largo plazo: nunca se termina de aprender a leer. Pero, hay otras aristas del problema, por ejemplo, la social: si los padres trabajan y apenas les alcanza para comer, cómo pensar que van a comprar libros. Las bibliotecas públicas casi no existen y si las hay sus recursos bibliográficos son de una pobreza franciscana. Un ejemplo de esto es el drama de la Biblioteca Nacional durante el actual gobiemo. ¿Quién puede familiarizarse con la lectura sino tiene un libro a la mano?

4.1. Otra cara del problema es el de la televisión ${ }^{12}$, la radio y los juegos mecánicos y electrónicos. Muchos maestros ignoran esta realidad y siguen creyendo que con condenarla es suficiente, pero ella es parte de la vida cotidiana de los estudiantes y, por lo tanto, nos obliga a tomarla en cuenta y a investigar cuál es el espacio que en esta nueva realidad le corresponde a la lectura, es decir, preguntamos: ¿Cuál es el papel de la lectura en este nuevo contexto?

5. Los libros de texto ${ }^{13}$ y las antologías de lectura son otra cara del problema. Se impone al niño y al joven lecturas que son totalmente ajenas a sus intereses y que se remiten a contextos y situaciones que desconoce y la mayoría de veces, como se trata de textos literarios, escritos en un español diferente al que el estudiante maneja, el resultado es que terminan odiando la lectura. Como hace más de medio siglo ya lo aconsejaba José Jiménez Borja, lo que al niño y al joven hay que darle es el acceso a bibliotecas para que él escoja lo que va a leer y vaya adquiriendo el gusto por la lectura.

Un colega colombiano habla de «la fatalidad de la lectura doligatoria» y cuenta (Burgos 2004) el caso de un muchacho que se negaba a leer:

Inquieto por esta situación, pues el joven era vivaz y muy hábil en la oralidad decidí indagar. Fnuna conversación que tuvimos, me dejó atónito: el joven de 16 años había leídb varios clásicos juveniles: Tom Sawyer, Ia 
Isla del Tesoro, Robinson Crusoe y otros. Me comentó sin prevención que en su casa tenía una surtida biblioteca, y que hasta los 13 años tuvo como hábito usurpar y disfnutar aquellos libros.

Todo cambió a partir de un arrso de español. Un profesor -quizás con la mejor intención-puso como trabajo final la lectura de La Ilíaday, para constatar que se hubiera dado, exigió un escrito donde se citaran todos los nombres, lugares y situaciones. Es decir, convirtió la ira de Aquiles, el sacrificio de Patroclo, las discusiones entre Zeus y Paseidón en un acto mecánico de copia.

Ni el estudiante mencionado, ni ningún otro alumo, disfrutó la lectura. Se les convirtió en una pesadilla, pues de esa nota dependía pasar la materia de español. Después de largas horas frente al texto, anotando cada uno de los nombres que aparecían, el muchacho llegó a tal nivel de estrés que no pudo terminar el trabajo. Finalmente entregó sólo una parte y, en consecuencia, perdió la materia. Desde ese entonces, con explicables razones, le tomó aversión a la lectura. [...]

Desde mi posición de profesor, pero recordando mi situación de alumo en el bachillerato, les quiero recordar a todos mis colegas latinoamericanos las sabias palabras de Borges al introducir uno de sus cursos de literatura: «Si estos textos les agradan, bien; y si no les agradan, déjenlos, ya que la idea de la lectura dbligatoria es una idea absurda, tanto valdría hablar de felicidad dbligatoria».

5.1. Los libros de texto agudizan el problema, además, porque sirven para «facilitar» la labor del docente, que se aferra a ellos y no sale un centímetro de ese marco y por ello obliga a los estudiantes a aprenderlos de memoria. Hay que desterrar los libros de texto. En estos últimos años, el estado peruano ha gastado millones de dólares en producirlos, en lugar de editar libros que vayan formando una biblioteca básica en cada escuela y en cada colegio; por ejemplo, en lugar de gastar tanto dinero en celebraciones pomposas, ¿no hubiese sido mejor invertirlo en hacer ediciones populares de las dbras de Jorge Basadre? Estoy absolutamente seguro de que el ilustre maestro se hubiese sentido feliz de que así fuera. Claro que el agudo sentido crítico del historiador molesta a nuestras clases dominantes que prefieren que sus obras no tengan mayor divulgación. Hoy que la sociedad peruana parece corromperse a pasos agigantados, por qué no acudir a Manuel González Prada, quien la vivisecciónó de manera cabal. Habría 
que editar sus obras para que nos provean de una actitud crítica que tanto necesita el Perú.

6. Ia formación de los profesores es otro factor clave. Las facultades de educación y los institutos pedagógicos centran su formación en la metodología pedagógica y dejan del lado el conocimiento científico. Un profesor sin una buena formación lingüŕstica es incapaz de lidiar con la realidad multilingüe y multidialectal que seguramente habrá en cada una de las aulas en las que enseñe. Por otra parte, ¿cómo un docente al que le cuesta trabajo expresarse y comprender un texto puede enseñar a sus alumnos a hablar con claridad y a entender discursos (textos) ? El profesor de Español debe tener una buena formación en lingüristica, debe conocer bien la fonética, la fonología, el léxico y la gramática del español, y por supuesto, manejar bien el castellano. Esto no quiere decir que al alumno hay que enseñarle esas ciencias, lo que el estudiante primario y secundario tiene que aprender es a usar su lengua.

6.1. Otro error grave en la formación de los maestros, sobre todo los de primaria, es pensar que como van a enseñar a niños no necesitan saber mucho, sólo tienen que hacerles agradables las clases. Para sintetizar algo, para ponerlo en «sencillo», hay que tener un buen conocimiento del asunto. Si no, es probable que lo importante se deje de lado y se enseñe lo superfluo, es decir, que la síntesis no sea la adecuada. ¿Cuántos profesores son capaces de hacer un buen resumen de un texto ${ }^{14}$

7. Otro hecho que, al parecer, no tiene que ver con la enseñanza de castellano, pero que es sumamente importante, es el del multilingüismo. En el Perú, y esto no sólo entre la gente común y corriente, se considera el multilingüismo como un problema. Se ignora que la condición multilingüe ha sido la normal (y sigue siéndolo en la mayoría de naciones) tanto en la sociedades como en los individuos, que el monolingüismo es una ideología que aparece en la época moderna con el surgimiento de las naciones en el Viejo Mundo, sobre todo en aquellas con gobiemos centralistas y autoritarios (España, Francia) , que ponen en práctica la política de imponer la lengua del poder central y desterrar las otras lenguas. 
7.1. Se considera como un lujo y no como una necesidad aprender una segunda o tercera lengua ${ }^{15}$, se deja este privilegio para los niños que van a colegios bilingües o a los que se pueden pagar cursos de lenguas extranjeras o viajes al extranjero para hacer cursos de inmersión. Es patético, que en el plan de estudios impuesto por el Ministerio de Educación los idiomas extranjeros aparezcan en la secundaria, cuando los idiomas se aprenden a hablar en la más tiema infancia.

7.2. Asimismo, las lenguas vemáculas son para la política educativa penuana un tema irresoluble. Por una parte, está la actitud de los padres que rechazan que sus hijos sean educados en ellas, y, por otra, la evidencia concreta de que el desarrollo cognitivo de un niño se ve afectado cuando su educación se hace mediante una lengua que no conoce. ¿Por qué no enseñarle en su lengua materna y paralelamente enseñarle castellano como segunda lengua? Quizás, porque se sigue pensando que el multilingüismo es un problema, como señalamos líneas arriba.

7.3. El papel del inglés, generalmente, es mal enfocado, hay quienes se horrorizan de los anglicismos y hay quienes muestran una total permisividad. Aquí, tenemos que analizar la situación y luego sacar conclusiones. Cuando se trata de terminología, lo que sucedió, sucede y seguirá sucediendo es que se tomen prestados vocablos del inglés, puesto que la ciencia, en general, se produce en $\mathrm{EE}$. UU. y no en los países hispanohablantes, por eso ella viene en inglés. Como ejemplo, casi risible, tenemos el de la RAE que trata de imponer que se escriba disquete, que por supuesto, nadie obedece. Otra cosa es el uso de vocablos y expresiones inglesas donde no son necesarias, pues, existen las correspondientes españolas o violentar la estructura del Español por influencia del inglés. Aquí, generalmente, se trata de usos de hablantes que no conocen bien el español (la radio, la televisión y la política peruana están plagadas de ellos) y llenan esos huecos con su poco o buen conocimiento del inglés, el fenómeno conocido como spanglish sobre el que corren ríos de tinta.

8. Todos tenemos algo de sádicos, no se necesita del psicoanálisis para saberlo. En el caso del profesor de Castellano esto aflora en su insistencia en priorizar la ortografía, sabe que ahí va a hacer sufrir al 
alumo, pues, enseña las reglas y su experiencia le dice que con ellas los alumnos no van a ningún lado. Quizás, si se pusiera a pensar se daría cuenta de que sólo los buenos lectores pueden dominarlas, y que en muchos casos, las reglas ortográficas que impone la RAE son irracionales ${ }^{16}$. Pero lo más grave es que inhibe al estudiante a escribir, porque éste hace un cálculo inmediato: cuanto menos escriba, menos faltas ortográficas cometeré.

9. Creo que no debo dejar de mencionar la tradicional insistencia en enseñar Gramática ${ }^{17}$. Desde hace algunas décadas, muchos estudiosos se han dado cuenta de lo discutibles que son los conceptos y la terminología de la Gramática, que en ese campo casi no se había avanzado nada desde la gramática clásica greco-latina, y, sus críticas no sólo apuntan a la gramática normativa, en la que el problema se agudiza, y que es la que se enseña en la escuela y el colegio. No hay que olvidar que la gramática originalmente se comienza a enseñar en el aprendizaje de una segunda lengua, es decir, a personas que manejaban ya otra lengua y conocían la gramática de esa lengua, por lo tanto, era una especie de gramática contrastiva; la Gramática de Nebrija es, esencialmente, una gramática del español para gente que no lo habla o que conoce la gramática latina. Algunos colegas intentan superar el impassey «enseñan»: «gramática «estructural», «funcional», «generativa», etc., como si bajo esos paraguas se cobijaran concepciones y metodologías consistentes y uniformes; por ejemplo, se habla de «estructuralismo»; no hay una gramática «estructural», sólo se trata de una etiqueta que comprende conceptos y métodos muy diferentes entre sí. Aquí, hay otra salida, el «análisis gramatical», la descuartización de oraciones inventadas, generalmente, muy largas, que entretiene a los estudiantes (tiene, eso sí, su aspecto lúdico), pero que no sirve en absoluto para aprender a usar el Español, puesto que los discursos (textos) se producen y se comprenden como un todo y de acuerdo con la situación en la que se habla. Seguramente un estudiante de Medicina aprende Anatomía haciendo la autopsia de un cadáver, pero dudo mucho de que se aprenda a hablar Español haciendo la autopsia de una oración, por muy larga y compleja que sea. Más aun, si hoy en día existen diversas páginas web que hacen este trabajo con la finalidad 
de lograr un análisis automático de los textos, por ejemplo: http:// uww.conexor.fi.

Y a propósito de Intemet, bien podría el profesor de castellano utilizar las múltiples páginas web que existen para facilitar su tarea y compatibilizar su enseñanza con la utilización de la computadora, que se ha convertido un instrumento cotidiano para niños y jóvenes. Por ejemplo: www.eldigoras.com.

10. Nada nos dice que la enseñanza del castellano en el Perú va a mejorar, por el contrario, los indicadores nos señalan que las cosas pueden empeorar pese a que pareciera que peor no pueden estar.

10.1. Una primera señal es la resolución ministerial 0048-2005 del Ministerio de Educación ${ }^{18}$ titulada: «Orientaciones y normas nacionales para la gestión en las instituciones de educación básica y educación técnico-productivas promulgada a comienzos de año por el ministro Javier Sota.

En este documento, el curso llamado «Comunicación integral» del que forma parte la enseñanza del español es una de las cuatro «materias» ${ }^{19}$ a estudiar en la educación inicial, pero ya en la educación primaria es una de cinco, además debe compartir su espacio con «Educación por el arter y, en secundaria, se convierte en una de siete y, además, debe compartir su espacio con «Educación por el arte» e «Idioma extranjero y/u originario», es decir, cada vez se enseña más pero se aprende menos.

Ya comentamos la aberrante ubicación de la enseñanza de idiomas extranjeros en este «plan de estudios», pero a eso se agrega el problema del número de horas que se asignan. En el caso de los idiomas extranjeros, que se «saltan a la garrocha» en la primaria, se les consigna dos horas a la semana y a «comunicación integral» tres, es decir, que no habrá forma que un alumno aprenda una segunda lengua, salvo que ocurra un milagro gracias a que las horas dedicadas a «religión» son las mismas que a la segunda lengua y, probablemente, también ocurra lo mismo en el aprendizaje del castellano, que como sabemos sólo tendrá parte de esas tres horas. ${ }^{20}$ 


\section{Notas}

1 «En las páginas que siguen usaremos los términos español y castellano camo sinónimos. Aunque la preferencia por uno de ellos significó en épocas pasadas una toma de conciencia política, respecto de la reunificación peninsular o la afirmación de la independencia de los países hispanoamericanos, lo cierto es que hoy empleamos ambos términos altemadamente y, con los dos por igual, designamos la lengua que si bien fue traída de Elropa por el colonizador hispánico, pronto acl imató en estas tierras y adquirió un perfil característico, así cono es propia y singular nuestra historia» (Alberto Escobar 1976) . Consúltese, asimismo, (Alonso 1943). Por supuesto que, dada la brevedad del artículo, considero que mudhas ideas no han sido desarrolladas.

2 Me refiero al documento de Ricardb Mbrales Basadre: Ell daminio del castellano, condición de crecimiento humano y unidad nacional [artículo publicado en el boletín electrónico del $\mathrm{QEE}$. Por supuesto que, dada la brevedad del artículo, considero que muchas ideas no han sido desarrolladas.

3 «Antes que nada, el lenguaje significa, tal es su carácter primordial, su vocación original que trasciende y explica todas las funciones que garantiza en el medio humano» (Bervesniste 1977: 219) .

4 A la asignatura se la denomina commicación integral.

5 Por ejemplo, así están organizados los libros de la asignatura (Diálogos) que edita la eoitorial Santillara.

6 Los trabajos de esta colega podrían socorrer a los inventores de la «comunicación integral».

7 Lo que señalo ya lo han dicho diversos estudiasos como Jasé Jiménez Borja, Luis Jaime Cisneros y Alberto Escobar, por mencionar a los més ilustres, pero, al parecer, la débil memoria de los peruanos lo ha olvidado.

8 «... en los países hispanoamericanos no existe la que pueda honradamente llamarse una política educacional en materia lingüística (y las excepciones confiman la regla). En países como los andinos el problema es más agudo porque ofrecen una fisonomía ciertamente bilingüe (español y lengua indígena) , y esta realidad no es ajena a la mayor o menor disposición de ánimo para divulgar los métoobs científicoss) (Luis Jaime Cisneros 1969: 10) .

9 «Una cosa es cierta. La lengua se estudia mal en la escuela y el colegio. La manejan mal los estudiantes. Nb la asimilan. No han aprendidb a gustarla. No saben valorarla. Es para ellos un elemento disociador antes que un vínculo de unión. Y otra cosa es peor: todos los profanos tienen recetas para la enfermedad. Entre estos profanos hay muchos que enseñan, varios que escriben textos escolares. Todos tienen, sin embargo, horror a la medicina y prefieren solazarse con el consejo vacilante de los percentiles, los «buenos autores» y el nunca bien entendido prestigio de la Real Academia») (Luis Jaime Cisneros 1969: 10) .

10 «Dizer o que se deve fazer é, no múnimo, fazer tabula rasa das diferencias: é acreditar que a verdade, se encontra em alguém ou em algum lugar e que é preciso lutar para atingi-la (ideal allturalmente perseguidb) , tentandb pôr em prática o que nos é ensinadb: Se é difícil, au talvez impossível, escapar a essa tendência teleológica, é, no entanto, 
possível buscar questiona-la para minimizar seus efeitos castradbres e avassaladores» (Coracini 1998: 53) .

11 Como señala Femando Savater en «Contra la ignorancia programada» (Suplemeno Babelia del diario El País) : «Frente a los constantes lamentos sobre el fracaso escolar y el aumento de la efectiva ignorancia entre los alumos, presentados como disfunciones del sistema, se pregunta: ¿y si tales carencias fuesen en realidad logros de una agenda no explícita, empeñada en conseguir una sustancial reducción de la inteligencia crítica, es decir, de la «aptitud fundamental del hambre para comprender a un tiempo el mundo que le ha tocado vivir y a partir de qué condiciones la rebelión contra ese mundo no se convierte en una necesidad moral»? Desde luego, la respuesta de Michéa es desafiantemente afimativa. Ia ideología del capital ismo globalizado quiere maximizar beneficios y minimizar la voluntad cívica. Para penpetuar y prolongar sus instrumentos tecnológicos le basta con formar una elite de privilegiados que reciban en centros privados (y selectivamente caros) una formación científica a la altura de los tiempos, debidamente exigente y disciplinada. Para los demás, basta con urdir un espacio de entretenimientos y juegos, abierto a la cháchara de los buenos sentimientos, en el que los profesores dejen de ser sujetos de saber y se conviertan en animadbres de indefinidos debates, concebidos según el modelo de los talk-shows televisivos, algo semejante a un gran parque de atracciones escolar. En este empeño colaboran ya voluntariosamente los nuevos pedagogos, desde la buena conciencia de un progresismo sin lágrimas ni coacciones que ha encontrado su primer y definitivo mandamiento en el «prohibido prohibin», completadb por su corolario «iconsiderad vuestros deseas camo realidades!». El resultado es esa proliferación de «borriquitos con chándal», según la ya irmortal acuñación de Sánchez Ferlosios.

12 «Cada vez es más frecuente ver que se ha dejado la educación a las pantallas de televisión, a programas frente a los arales los niños se pasan horas y días, sustituyénobse el contacto de persona a persona y el compromiso de educar; es decir, el compromiso de que alguien se responsabilice del mundo ante los niños, de que alguien transmita el aprecio por lo humano. ... El problema de los niños no es que vean mucha o poca televisión, sino que la vean solos. Es decir, que la televisión se convierta en sustituto de las personas que deberían estar con ellos; que la televisión se convierte en el único elemento familiar estables (Savater 1997: 77 y 81) .

13 «Hace cincuenta años, todo lo que debía aprenderse en la escuela se encontraba en un libro, en el pizarrón o en lo que dictaba el maestro. Los libros representaban el cuenpo del conocimiento que debía ser transmitido, reproducido, examinado. Ell resto era precisiones o comentarios, las pequeñas bromas o apostillas del profesor, los métodos memotécnicos para recordar las fómulas químicas o los pronombres latinos. La autoridad del libro de texto era indiscutible, aun cuando su contenido adbleciera de mala información (la ciencia de mi escuela era de antes de Einstein) , o fuera racista (como sucedía en historia) , cambiante (el mapa de Europa) , etnocéntrico (en todas las materias) » (Margaret Meek 2004: 247). [Hay que anotar que el original inglés es de 1971, es decir, la autora habla de la Inglaterra de comienzos del siglo XX, sin enbargo, casi parece que pinta la realidad penuana actual] . 
14 «El maestro entendido como la persona que se encarga de la primera educación de los niños, es en mi opinión, el elemento más importante de la educación. Todos los demás, me refiero a los catedráticos de universidad, los artistas, los literatos y los propios políticos, no somos más que maestros de segunda; es decir, maestros que venimos después de que los maestros de primera han cumplido su misión. Por ello, si esos maestros de primera no han cumplido bien su función, es muy difícil que nosotros tengamos ocasión de llevar a cabo alguna labor especialmente relevantes (Savater 1997: 65-66).

15 En Francia, por ejemplo, el Ministerio de Educación ha aprobado un dispositivo para que los niños aprendan una segunda lengua en la primaria y una tercera en el colegio: «U' ambition, dans les cinq ans, est que tous les élèves de 6ème apprennent deux langues vivantes, l'une commencée à l'école primaire, l' autre débutée au college. ... N’est-il pas prématuré de vouloir enseigner les langues étrangères dès le cours moyen, voire le caurs élémentaire? Y a-t-il un âge idéal parr apprendre les langues et, si aii, quel est-il? Les recherches faites en neurobiologie démontrent que l'enfant dans la période de six à douze mois perd de ses capacités distinctives. Ayant entendu dans le ventre de sa mère la musique de sa langue matemelle, le nouveau-né est extrêmement réceptif et est capable de faire la distinction entre des signaux linguistiques très fins corme -ba et -pa. Ses compétences ne sont pas simplement d'ordre phonétique, mais également prosodique (rythme et intonation). Les intonations qu' imprime la structure des phrases lui donnent de précieuses informations syntaxiques sur sa langue matemelle. S' qpère ensuite une sclérose des synapses correspondant à l' absence de stimuli spécifiques à une langue. Ainsi un enfant japonais recomnaissant le système phonologique propre à sa langue matemelle confondra rapidement le -l et le -r. Cependant cette récession n' est pas irréversible et jusqu' à l'âge de dix ans l'enfant est capable $d^{\prime}$ acquérir une compétence comparable à celle des locuteurs natifs» X. BIHAN en www.eldigoras.com.

16 «tb me quejo, pues, de las faltas de prescripción autoritaria de esta nueva Ortografía de la Lengua Española, como hacen algunos que son más conservadores que la Real, como José Mbreno de Alba, que critican que la Real dé libertades. Me quejo, sí, de que se mantenga en una irracionalidad radical. Me quejo de que no continuase las reformas que dejó estancadas en 1844 e incluso en 1952, cuando adelanto mucho más que en esta «novísima» Ortografía de 1999, casi idéntica a las Novísimas Normas de 1952. Casi medio siglo perdido, o más, porque hemos retrocedido con respecto a la etapa anterior a 1844..». Roberto Hemández Montoya, citado en Luis Miranda (2002: 192-193) .

17 «En 1924 decía Manuel de Montolíu, encargado por el Centro de Estudios Históricas de Madrid para dirigir el Instituto de Fi lología de Buenos Aires: «Nb trataré de disautir ni de fijar las reglas del lenguaje correcto, no voy a enseñar dogmáticamente el buen castellano», «[1] a enseñanza ha de consistir esencialmente en un ejercicio intenso y metodizado de la facultad natural de hablar... En cambio, la enseñanza de la gramática consiste esencialmente en abstraer las leyes que rigen muestra expresión hablada y formularla teóricamente. Es una disciplina científica»; « [s] eparando francamente la enseñanza del lenguaje de la gramática se pocrá acabar con las falsas orientaciones que 
hasta ahora han perturbadb la enseñanza de la última» Boletín del Instituto de Filología, (Buenos Aires, 1926, tomo I, p. 96, 99, 100)» (Luis Jaime Cisneros 1969: 21) [i1924!] .

18 «En la mayoría de nuestros países, el Ministerio de Educación establece los programas de Lengua española. Explica qué debe enseñarse. Y da directivas sobre cómo ha de impartirse la enseñanza. En principio, así debe ser. Algunos de los programas son fintos del trabajo de conisiones técnicas especiales; casi no hay lingüistas en ellas, aunque sí profusos maestros con años de servicio evidentes. Lo grave es que, en rarísimas ocasiones, esos programas vienen fundamentados, como suele ocurrir en Europa. Y aunque es verdad que muchos de ellos incluyen directivas para el profesorado, la mayoría de las veces no aluden éstas a los dbjetivos científicos de la disciplina, ni a la metodología a seguir, sino que están dedicadas a los procedimientos administrativos que servirán para evaluar la progresión de la enseñanza. Como los programas se redactan para que los cumpla el profesorado, ocurre que no ha sido hasta ahora posible obtener una doctrina coherente que pueda presidirlos. Por eso todos repiten una funesta perspectiva: gramática tradicional inspirada en ideales nomativos y fundada en la realidad de la palabra, que aparece así como fuente de toda inspiración» (Luis Jaime Cisneros 1969: 12-13) .

19 Los nombres de las asignaturas son de antología, aparte de la de «commicación integral» que ya comentamos, se tiene: «lógico-matemática», «personal social» y «ciencia y ambientes.

20 Me parece aquí sumamente pertinente citar a Cereijidb y Reinking (2003: 119-120) : «EI problema de orden práctico es hoy cómo democratizar a alguien que fue educado desde una edad temprana para declararse a sí mismo una oveja (Salmos 95:7: «..porque él es nuestro Dios y nosotros el pueblo que él apacienta, rebaño de su mano.») ; cómo promover una intenpretación de la realidad que sea compatible con la ciencia modema a un cerebro que desde la infancia fue doligado a creer en milagros (Jiran 20:29: «Dícele Jesús ... bienaventurados los que creerán sin haber visto.») ; cómo desarroll lar la ciencia en una población a la que siempre se le hizo creer que la ciencia es exactamente lo mismo que la investigación». 


\section{Referencias bibliográficas}

ALONSO, Amado (1943) : Castellano, Español, Idioma Nacional. Historia espiritual de tres nombres. Losada, Buenos Aires.

BENENISIE, Émile (1977) : Problemas de Lingüŕstica General II. Siglo XXI, México.

BORDEIOIS, Ivomne (2003) : La palabra amenazada. Libros del Zorzal, Buenos Aires.

BURGOS, Félix Manuel (2004) : «La fatalidad de la lectura obligatoria». BBC en español (02/11/04) .

CEREIJIDO, Marcelino y RETNKMNG, Laura (2003) : La igmorancia debida. Libros del Zorzal, Buenos Aires.

CISNEROS, Luis Jaime (1969) : Lengua y enseñanza. Studium, Lima.

CORACINI, María José (1998) : «A teoria e a prática: a questao da diferenta no discurso sobre e da sala de aula». Delta, 14/1; p. 53.

ESCOBAR, Alberto (1976) : Ienguaje. INDE, Lima.

MEHK, Margaret (2004) : En tomo a la cultura escrita. FCE, México.

MIRANDA, Luis (2002) : «El marketing llegó a la RAE». Revista de Ienguas Modernas, 5; pp. 192-193.

SANIAFIUA, L. (2001) : «Tres matrices del lenguaje-pensamiento». Signa, 10, pp. 91-98.

SAVATER, Fernando (1997) : «El valor de educar». En: Conferencias en Lima. UPC, Lima.

SECO, Manuel: Sobre la Real Academia, la norma y los hablantes. (www.edilgoras.com)

SUBIRATS, Carlos (2000) : «Intransiciones lingüísticas». En: Eduardo Subirats (ed.) : Intransiciones. Crítica de la aultura española. Biblioteca Nueva, Madrid. 